\title{
Kelimpahan Cacing Tanah pada Beberapa Jenis Tegakan Pohon di Wanagama I
}

\section{The Abundance of Earthworms under Several Tree Stands in Wanagama I}

\author{
Haryono Supriyo $^{1 *}$, Musyafa ${ }^{1}$, Arom Figyantika ${ }^{1}$, dan Saptuti Gamayanti ${ }^{2}$ \\ ${ }^{1}$ Jurusan Budidaya Hutan, Fakultas Kehutanan, Universitas Gadjah Mada \\ Jl Agro No. 1 Bulaksumur Yogyakarta 55281 \\ ${ }^{2}$ Alumni Jurusan Budidaya Hutan, Fakultas Kehutanan, Universitas Gadjah Mada Yogyakarta \\ E-mail: haryonosupriyo@yahoo.com*Penulis untuk korespondensi
}

\begin{abstract}
Earthworms feed exclusively on dead organic matter (OM). The earthworm population is regulated by organic matter availability and soil characteristics. The aim of the research was to investigate the effect of seasonal change to the abundance and biomass of earthworms in Wanagama I. Collection of the soil samples was conducted from a quadrangle 25 x $25 \times 25 \mathrm{~cm}$ with the depth of $0-10,10-20$ and $20-30 \mathrm{~cm}$ with 5 replications under stands of Glyricidae, Leucaena, Teak, Acacia, Eucalyptus and Mahogany. Soil samples were taken at rainy season (February), early dry season (July) and dry season (October) 2004. The earthworms were manually extracted from soil samples and the abundance was stated as number and biomass of dry weight. The result showed the abundance and biomass of earthworms were high only in February at the soil depth of $0-10 \mathrm{~cm}$. The highest number of earthworm and biomass was found in Mahogany stand $\left(224,000 \text { individual.ha }{ }^{-1} / 105.6 \mathrm{~kg}^{-h^{-1}}\right)^{-}$. Multiple linier regression analysis showed that abundance of earthworms was affected by soil moisture content, while the biomass of earthworms was affected by soil $\mathrm{pH}$ and bulk density (aeration).
\end{abstract}

Key words: Abundance, earthworms, tree stands

\begin{abstract}
Abstrak
Bahan organik yang sudah mati merupakan makanan utama bagi cacing tanah. Ketersediaan bahan organik dan sifat-sifat tanah memengaruhi kelimpahan cacing tanah. Penelitian ini bertujuan untuk mengetahui pengaruh perbedaan musim terhadap kelimpahan dan biomassa cacing tanah di Wanagama I. Pengambilan sampel dilakukan pada plot berukuran 25x 25 x 25 cm pada kedalaman 0-10, 10-20 dan 20-30 cm dengan $5 x$ ulangan, di bawah tegakan Gamal, Lamtoro, Jati, Akasia, Eukaliptus dan Mahoni. Sampel tanah diambil pada musim hujan (Februari), awal musim kemarau (Juli), dan musim kemarau (Oktober) 2004. Kelimpahan cacing tanah diketahui dengan menghitung cacing tanah yang telah diekstrak secara manual dari sampel tanah, biomassa cacing tanah yang didapat dioven sehingga didapat berat konstannya. Hasil penelitian menunjukkan bahwa kelimpahan dan biomassa cacing tanah yang tinggi hanya terdapat pada bulan Februari pada kedalaman tanah 0-10 cm. Kelimpahan dan biomassa cacing tanah tertinggi terdapat pada tegakan mahoni $\left(224,000\right.$ individu.ha ${ }^{-1} / 105.6$ kg.ha $^{-1}$ ). Analisis regresi menunjukkan bahwa kelimpahan cacing tanah dipengaruhi oleh kelembaban tanah, sedangkan biomassa cacing tanah dipengaruhi oleh $\mathrm{pH}$ dan berat volume tanah (aerasi).
\end{abstract}

Kata kunci: Kelimpahan, cacing tanah, tegakan pohon

Diterima: 02 Juni 2009, disetujui: 21 Januari 2010

\section{Pendahuluan}

Cacing tanah memegang peranan sangat penting dalam menjaga kesuburan tanah baik secara fisik, kimia maupun biologis. Secara fisik cacing tanah berperan dalam mencampurkan bahan organik (BO) kasar ataupun halus antara lapisan atas dan bawah sehingga penyebarannya lebih merata. Aktivitas ini juga menyebabkan 
terbentuknya struktur tanah yang stabil dan gembur, aerasi lebih baik, infiltrasi air lebih lancar sehingga mengurangi erosi. (Peres et al., 1998; Chuasavathi et al., 2001; Marhan et al., 2006).

Cacing tanah diduga merupakan makro fauna paling penting di dalam tanah, karena memakan BO dan mineral tanah dalam jumlah sangat banyak. Ekresi (casts) yang dikeluarkan cacing tanah tidak kurang dari 34 ton/ha/th. Secara biologis, ekresinya banyak mengandung bakteri dekomposer yang berperan dalam daur unsur hara. Di samping itu juga mengandung banyak $\mathrm{BO}$, unsur hara $\mathrm{N}, \mathrm{P}$ dan $\mathrm{K}$ dan tingginya kation basa tertukar $(\mathrm{Ca}, \mathrm{Mg}, \mathrm{Na}, \mathrm{K})$ sehingga $\mathrm{pH}$ tanah cenderung ke arah netral dan mempunyai nilai kapasitas pertukaran kation (KPK) yang tinggi (Brady, 1985; Sabrina et al., 2009).

Kepadatan populasi cacing tanah dipengaruhi oleh sifat fisik-kimia tanah, seperti kelembaban, suhu, aerasi, $\mathrm{pH}$ dan tersedianya BO. Pada tanah yang berbeda faktor fisik dan kimianya tentu kepadatan populasi cacing tanahnya juga berbeda. Jenis tegakan sangat menentukan populasi cacing tanah, kualitas sersah (litter) dan iklim mikro yang berbeda akan berpengaruh terhadap jenis dan kepadatan populasi cacing tanah. Untuk mengukur aktivitas cacing tanah dapat digunakan parameter jumlah organisme dan biomassa organisme tersebut (Smith et al., 2006).

Di Hutan Wanagama I terdapat beberapa jenis tegakan. Karena secara umum kegiatan pembangunan hutan dimaksudkan untuk kepentingan produksi, konservasi maupun pengawetan tanah dan air, penelitian tentang kesuburan tanah yang biasanya dikaitkan dengan cacing tanah perlu dilakukan pada jenis-jenis tegakan terutama pada tegakan komersial.

Penelitian ini bertujuan mengetahui pengaruh musim terhadap kelimpahan dan biomassa cacing tanah pada beberapa jenis tegakan di Hutan Wanagama I pada beberapa kedalaman tanah dan untuk mengetahui faktorfaktor lingkungan yang memengaruhinya.

\section{Metode Penelitian}

Penelitian ini dilakukan di petak 5, 14, dan 17 Hutan Wanagama I Gunung Kidul pada tegakan gamal (Gliricidia sepium), lamtoro (Leucaena leucocephala), jati (Tectona grandis), akasia (Acacia mangium), eukaliptus (Eucalyptus urophylla), dan mahoni (Swietenia macrophylla). Tegakan gamal, lamtoro dan jati berumur 12 tahun sedangkan tegakan akasia dan eukaliptus berumur 21 tahun serta tegakan mahoni berumur 34 tahun (Gambar 1).

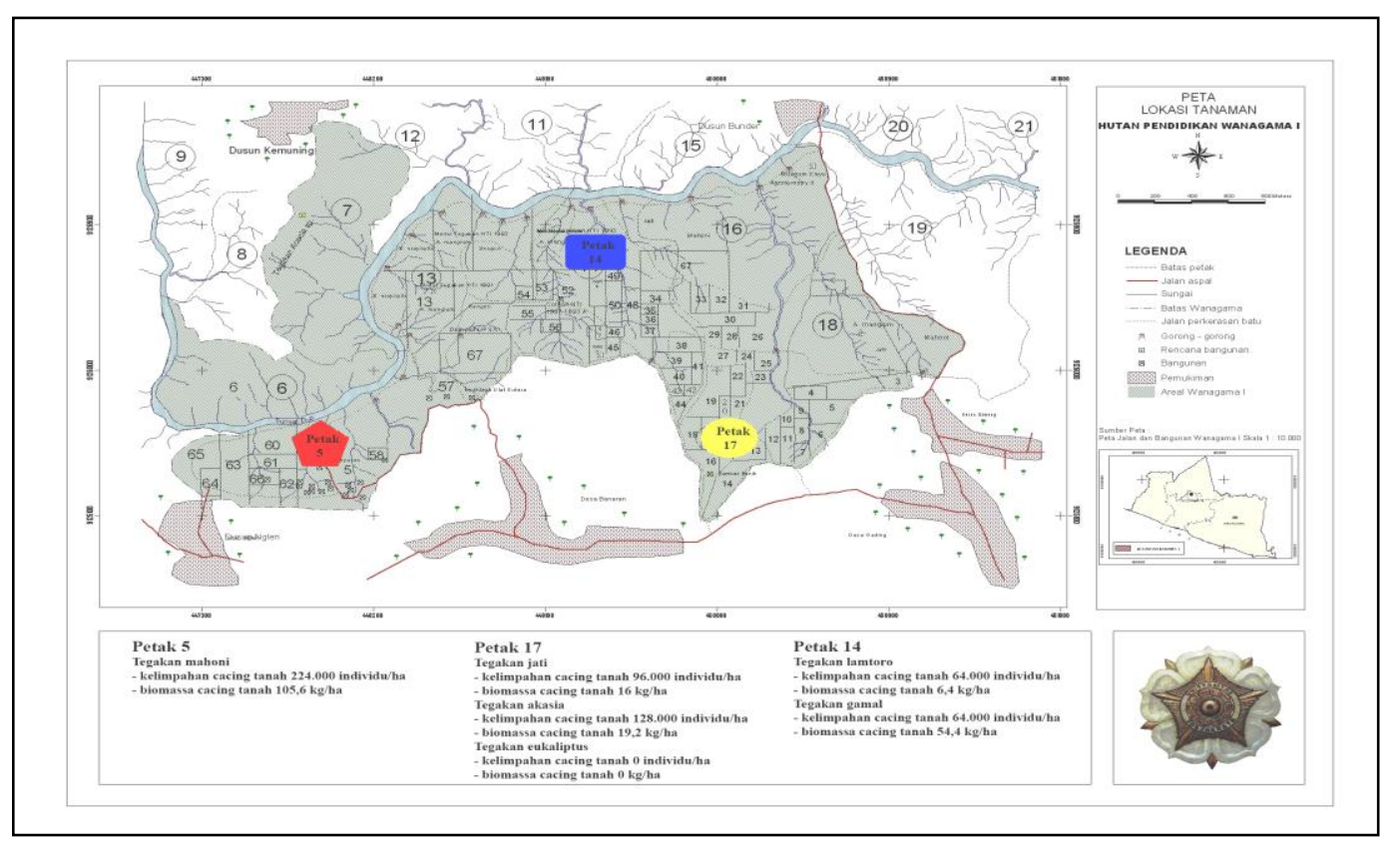

Gambar 1. Peta sebaran cacing tanah di Hutan Pendidikan Wanagama I. 
Tanah Wanagama berkembang dari batuan induk gamping (limestone) dengan ketinggian antara 200-270 m dpl, topografi bergelombang berbukit. Curah hujan rata-rata sebesar 1.900 $\mathrm{mm} / \mathrm{th}$, bulan kering > 4 bulan, suhu berkisar $23,2-32,4^{\circ} \mathrm{C}$ dan kelembaban udara $65-90 \%$. Dari kondisi tersebut di atas terbentuk tanah: Vertisol (Grumusol), Alfisol (Mediteran) dan Entisol (Lithosol) (Supriyo, 2004).

Pengambilan sampel dilakukan pada bulan Februari (musim hujan), Juli (peralihan antara musim hujan dan kemarau), dan Oktober (musim kemarau) tahun 2004. Pengambilan sampel tanah dilakukan dengan membuat lubang berukuran 25 x $25 \mathrm{~cm}$ pada tanah dengan kedalaman $0-10 \mathrm{~cm}$, 10-20 $\mathrm{cm}$ dan $20-30 \mathrm{~cm}$ dengan 5 ulangan secara random untuk tiap jenis tegakan. Cacing tanah disortasi dari sampel tanah secara manual kemudian dihitung jumlah dan biomassa berat keringnya per $\mathrm{m}^{2}$. Menghitung biomassa seresah dengan cara mengoven seresah pada suhu $65^{\circ}-70^{\circ} \mathrm{C}$ sampai mencapai berat konstan, kemudian biomassa seresah dihitung dalam ton/ha. Pengujian kandungan $\mathrm{C}$ organik tanah dengan menggunakan metode Walkley dan Black. Bahan organik (BO) tanah diperoleh dengan mengalikan kadar $\mathrm{C}$ organik tanah dengan besaran angka 1,724. $\mathrm{pH}$ tanah diukur menggunakan $\mathrm{pH}$ meter. Pengujian berat volume (bulk density) tanah menggunakan metode ring tanah (Hesse, 2002).

\section{Hasil dan Pembahasan}

Kelimpahan dan biomassa cacing tanah pada beberapa jenis tegakan di Hutan pendidikan Wanagama I hanya ditemukan pada saat musim hujan, sedangkan pada saat musim pancaroba dan kemarau tidak ditemukan cacing tanah. Hal ini dapat disebabkan oleh musim pancaroba dan kemarau, tanah pada tempat penelitian dalam keadaan kering dan keras (Tabel 1 dan 2) sehingga menyebabkan kelimpahan dan biomassa cacing tanahnya akan menurun, sebab cacing tanah lebih senang hidup pada tanahtanah yang lembab. Hal tersebut diperjelas oleh Brown (1978) bahwa adanya musim kemarau yang panjang dan permukaan tanah yang kering menyebabkan jumlah populasi cacing tanah menurun secara drastis.

Pada musim hujan kelimpahan dan biomassa cacing tanah tertinggi pada kedalaman 0-10 cm, sedangkan pada kedalaman $10-20 \mathrm{~cm}$ dan 20-30 $\mathrm{cm}$ pada ketiga musim tidak ditemukan sama sekali. Hal ini dapat dijelaskan dengan semakin bertambahnya kedalaman tanah maka semakin sedikit bahan organik, dan oksigen yang tersedia bagi cacing tanah. Hal ini sesuai dengan hasil penelitian kelimpahan cacing tanah pada tegakan Pinus merkusii (umur tegakan 5, 7, 22, dan 28 tahun) di RPH Karanganyar, BKPH Sumberwringin, KPH Bondowoso, Jawa Timur. Hasil penelitian menunjukkan bahwa kelimpahan cacing tanah tertinggi terdapat pada musim penghujan dan pada kedalaman tanah $0-10 \mathrm{~cm}$ (Supriyo et al., 2007a). Hasil penelitian tersebut juga sama dengan hasil penelitian tentang kelimpahan cacing tanah di bawah beberapa jenis tegakan (mahoni, jati dan pinus) di Sempolan, Jember, Jawa Timur (Supriyo et al., 2007b).

Pada tegakan eukaliptus tidak ditemukan cacing tanah pada musim hujan, kemarau dan pancaroba serta pada ketiga kedalaman tanah. Hal ini disebabkan oleh sersahnya mengandung minyak atsiri, kandungan lignin yang tinggi $(24,48 \%)$ dan kandungan selulose rendah. Kandungan zat kimia lain tersebut di dalam daun eukaliptus tidak disukai atau bahkan meracun bagi cacing tanah (Tian, 1992).

Kelimpahan cacing tanah tertinggi terdapat pada tegakan mahoni (224.000 individu/ha), akasia (128.000 individu/ha), jati (96.000 individu/ha), lamtoro (64.000 individu/ha), gamal (64.000 individu/ha), dan eukaliptus $(0$ individu/ha) (Gambar 2). Jumlah ini sangat kecil dibandingkan dengan jumlah cacing tanah pada tanah hutan yaitu 500.000-2.500.000 individu/ha (Pritchett, 1979). Hal ini disebabkan oleh kelas tekstur tanah di Wanagama adalah lempung (clay) sehingga aerasi tanahnya jelek (poor aeration). Supriyo et al., (2007b) mengemukakan bahwa pada beberapa tegakan hutan di Sempolan, Jember, Jawa Timur jumlah cacing tanah berkisar antara 48.000-749.000 individu/ha, hal ini karena tekstur tanahya pasir (sandy) sehingga aerasi tanahnya sangat baik. 
Tabel 1. Biomassa seresah dan kadar lengas tanah pada beberapa jenis tegakan di Hutan Pendidikan Wanagama I.

\begin{tabular}{llcccc}
\hline \hline Tegakan & \multicolumn{1}{c}{ Musim } & $\begin{array}{c}\text { Biomassa Seresah } \\
\text { (ton/ha) }\end{array}$ & $\begin{array}{c}\text { Kadar Lengas } \\
\text { Tanah 0-10 cm }(\%)\end{array}$ & $\begin{array}{c}\text { Kadar Lengas } \\
\text { Tanah10-20 cm }(\%)\end{array}$ & $\begin{array}{c}\text { Kadar Lengas } \\
\text { Tanah } \mathbf{- 3 0} \text { cm }(\%)\end{array}$ \\
\hline \hline Gamal & Hujan & 2,29 & 50,28 & 59,23 & 62,42 \\
& Pancaroba & 2,31 & 33,61 & 42,92 & 45,79 \\
& Kemarau & 2,45 & 19,23 & 35,32 & 43,24 \\
\hline Lamtoro & Hujan & 2,00 & 51,57 & 53,96 & 57,47 \\
& Pancaroba & 2,26 & 33,64 & 41,81 & 48,32 \\
& Kemarau & 2,06 & 25,55 & 40,96 & 44,44 \\
\hline Jati & Hujan & 2,94 & 50,59 & 52,98 & 56,46 \\
& Pancaroba & 3,59 & 29,46 & 39,28 & 40,69 \\
& Kemarau & 6,76 & 21,40 & 25,58 & 38,12 \\
\hline Akasia & Hujan & 6,09 & 55,81 & 57,71 & 60,46 \\
& Pancaroba & 5,32 & 38,6 & 40,84 & 43,05 \\
& Kemarau & 5,02 & 26,16 & 35 & 35,82 \\
\hline Eukaliptus & Hujan & 8,05 & 49,19 & 52,02 & 56,13 \\
& Pancaroba & 4,11 & 33,62 & 40,55 & 38,58 \\
& Kemarau & 6,13 & 32,16 & 36,32 & 36,06 \\
\hline Mahoni & Hujan & 9,21 & 58,29 & 60,48 & 63,37 \\
& Pancaroba & 9,95 & 45,12 & 42,70 & 43,55 \\
& Kemarau & 11,71 & 20,94 & 37,61 & 39,79 \\
\hline \hline
\end{tabular}

Tabel 2. Suhu dan kelembaban udara pada beberapa jenis tegakan di Hutan Pendidikan Wanagama I.

\begin{tabular}{|c|c|c|c|}
\hline Tegakan & Musim & Suhu Udara ( $\left.{ }^{0} \mathrm{C}\right)$ & "Kelembaban Udara (\%) \\
\hline \multirow[t]{3}{*}{ Gamal } & Hujan & 30 & 77 \\
\hline & Pancaroba & 31 & 64 \\
\hline & Kemarau & 37 & 51 \\
\hline \multirow[t]{3}{*}{ Lamtoro } & Hujan & 28 & 80 \\
\hline & Pancaroba & 30 & 76 \\
\hline & Kemarau & 36 & 50 \\
\hline \multirow[t]{3}{*}{ Jati } & Hujan & 30 & 75 \\
\hline & Pancaroba & 30 & 66 \\
\hline & Kemarau & 37 & 50 \\
\hline \multirow[t]{3}{*}{ Akasia } & Hujan & 31 & 73 \\
\hline & Pancaroba & 31 & 64 \\
\hline & Kemarau & 32 & 56 \\
\hline \multirow[t]{3}{*}{ Eukaliptus } & Hujan & 33 & 66 \\
\hline & Pancaroba & 35 & 55 \\
\hline & Kemarau & 35 & 50 \\
\hline \multirow[t]{3}{*}{ Mahoni } & Hujan & 24 & 84 \\
\hline & Pancaroba & 28 & 80 \\
\hline & Kemarau & 30 & 62 \\
\hline
\end{tabular}

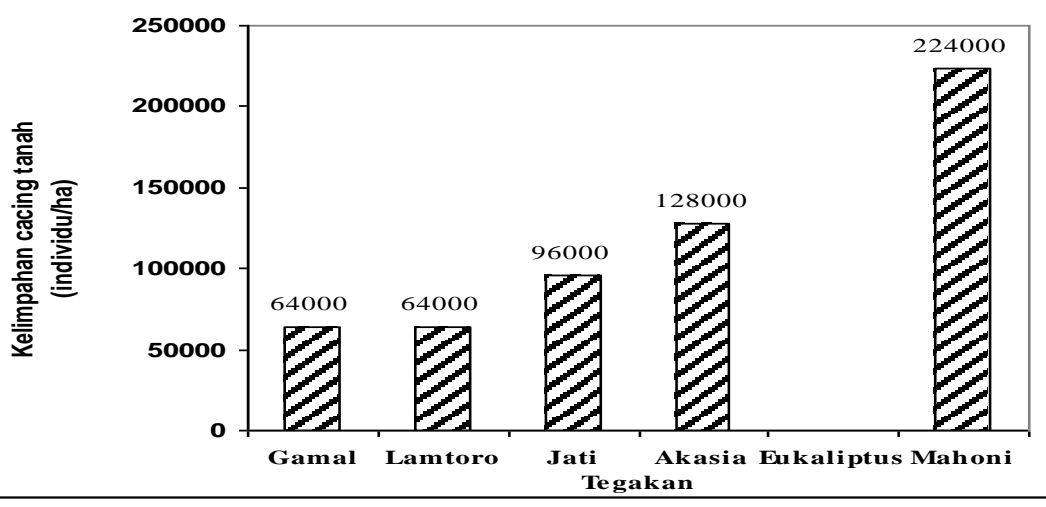

Gambar 2. Kelimpahan cacing tanah kedalaman $0-10 \mathrm{~cm}$ pada musim penghujan pada beberapa jenis tegakan di Wanagama I Gunungkidul, Yogyakarta. 
Biomassa cacing tanah tertinggi terdapat pada tegakan mahoni $(105,6 \mathrm{~kg} / \mathrm{ha})$, gamal $(54,4$ $\mathrm{kg} / \mathrm{ha})$, akasia (19,2 kg/ha), jati (16 kg/ha), lamtoro $(6,4 \mathrm{~kg} / \mathrm{ha})$ dan eukaliptus $(0 \mathrm{~kg} / \mathrm{ha})$ (Gambar 3). Kelimpahan dan biomassa cacing tanah yang tertinggi pada tegakan mahoni disebabkan kandungan bahan organiknya $(10,33 \%)$ lebih tinggi daripada tegakan lain, berat volume tanahnya relatif kecil $\left(1,46 \mathrm{~g} / \mathrm{cm}^{3}\right)$ sehingga ruang pori udaranya lebih banyak, dan pH tanahnya mendekati netral $(6,70)$ (Tabel 3). Biomassa cacing tanah mempunyai variasi yang sangat besar antara 110-1.100 kg/ha (Brady, 1985), hasil penelitian ini sangat rendah karena kelas tekstur tanahnya geluh lempungan (clay loam) sampai lempung.

Hasil analisis regresi menunjukkan bahwa nilai $\mathrm{R}^{2}$ kadar lengas tanah terhadap kelimpahan cacing tanah sebesar 0,828 . Hal ini berarti bahwa $82,8 \%$ kelimpahan cacing tanah dipengaruhi oleh variabel kadar lengas tanah. Semakin tinggi kadar lengas tanah maka kelimpahan cacing tanah juga semakin besar. Kadar lengas tanah sangat berpengaruh pada kelimpahan cacing tanah karena kelembaban merupakan faktor yang memengaruhi distribusi cacing tanah, karena air mengisi $75-90 \%$ dari berat tubuh cacing tanah. Hasil analisis regresi untuk biomassa cacing tanah menunjukkan bahwa nilai $\mathrm{R}^{2} \mathrm{pH}$ tanah dan berat volume tanah terhadap biomassa cacing tanah sebesar 0,914. Hal ini berarti bahwa 91,4\% kelimpahan cacing tanah dipengaruhi oleh variabel $\mathrm{pH}$ tanah dan berat volume tanah. Dengan adanya $\mathrm{pH}$ tanah yang netral memungkinkan cacing tanah mampu melakukan proses pencernaan makanan dengan baik dan didukung dengan adanya berat volume tanah yang rendah akan menyebabkan aerasi dan drainasi tanah akan baik sehingga biomassa cacing tanahnya akan meningkat.

Karakteristik cacing tanah dari hasil identifikasi oleh Fakultas Biologi UGM adalah: panjangnya $10-20 \mathrm{~cm}$, diameternya $3-6 \mathrm{~mm}$, clitelum berbentuk seperti cincin dan warnanya dari abu-abu sampai coklat kehitaman, kulit dorsal berwarna coklat gelap dan ventral berwarna abu-abu. Berdasarkan karakteristik tersebut cacing tanahnya dapat diklasifikasikan sebagai Pheretima sp. (suku Megascolidae). Menurut Suin (1977) sebagian cacing tanah di Indonesia termasuk suku Glossocolecidae dan Megascolidae (Gambar 4).

Tabel 3. Sifat fisika dan kimia tanah pada beberapa tegakan di Hutan Pendidikan Wanagama I.

\begin{tabular}{lccccl}
\hline \hline Tegakan & $\begin{array}{c}\text { Kedalaman Tanah } \\
(\mathbf{c m})\end{array}$ & $\mathbf{p H}$ Tanah & $\begin{array}{c}\text { Berat Volume } \\
\text { Tanah }\left(\mathbf{g} / \mathbf{c m}^{\mathbf{3}}\right)\end{array}$ & $\begin{array}{c}\text { Bahan Organik } \\
\text { Tanah }(\mathbf{\%})\end{array}$ & \multicolumn{1}{c}{ Kelas Tekstur } \\
\hline \hline Gamal & $\mathbf{0}-\mathbf{1 0}$ & $\mathbf{5 , 5 9}$ & $\mathbf{1 , 6}$ & $\mathbf{3 , 2 8}$ & Lempung pasiran \\
& $10-20$ & 5,15 & 1,79 & 1,98 & Lempung \\
& $20-30$ & 5,22 & 1,84 & 2,19 & Lempung \\
\hline Lamtoro & $\mathbf{0}-\mathbf{1 0}$ & $\mathbf{5 , 7 6}$ & $\mathbf{1 , 3 9}$ & $\mathbf{3 , 7 4}$ & Geluh lempung pasiran \\
& $10-20$ & 5,68 & 1,46 & 3,76 & Geluh lempung pasiran \\
& $20-30$ & 5,49 & 1,96 & 3,88 & Lempung pasiran \\
\hline Jati & $\mathbf{0}-\mathbf{1 0}$ & $\mathbf{5 , 4 7}$ & $\mathbf{1 , 5 1}$ & $\mathbf{4 , 0 4}$ & Geluh lempung pasiran \\
& $10-20$ & 5,11 & 1,55 & 2,99 & Lempung pasiran \\
& $20-30$ & 5,2 & 1,65 & 1,99 & Lempung \\
\hline Akasia & $\mathbf{0}-\mathbf{1 0}$ & $\mathbf{5 , 4 5}$ & $\mathbf{1 , 5 7}$ & $\mathbf{6 , 3 0}$ & Geluh lempung pasiran \\
& $10-20$ & 5,71 & 1,64 & 2,61 & Lempung \\
& $20-30$ & 6,11 & 1,73 & 1,36 & Lempung \\
\hline Eukaliptus & $\mathbf{0}-\mathbf{1 0}$ & $\mathbf{5 , 0 6}$ & $\mathbf{1 , 6 9}$ & $\mathbf{3 , 8 6}$ & Geluh lempung pasiran \\
& $10-20$ & 4,99 & 1,73 & 2,34 & Geluh lempung pasiran \\
& $20-30$ & 5,02 & 1,97 & 2,00 & Lempung pasiran \\
\hline Mahoni & $\mathbf{0}-\mathbf{1 0}$ & $\mathbf{6 , 7 0}$ & $\mathbf{1 , 4 6}$ & $\mathbf{1 0 , 3 3}$ & Geluh pasiran \\
& $10-20$ & 6,97 & 1,63 & 9,22 & Geluh pasiran \\
& $20-30$ & 6,90 & 1,65 & 6,31 & Geluh pasiran \\
\hline \hline
\end{tabular}




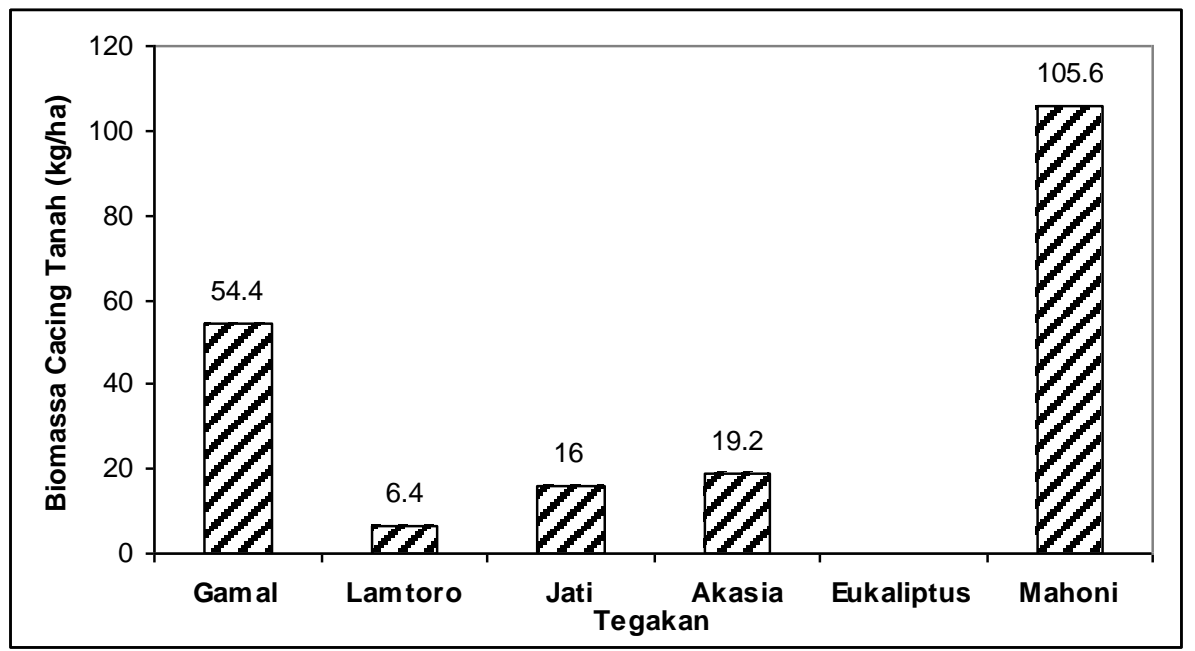

Gambar 3. Biomassa cacing tanah kedalaman tanah $0-10 \mathrm{~cm}$ pada musim penghujan pada beberapa jenis tegakan di Wanagama I Gunungkidul, Yogyakarta.

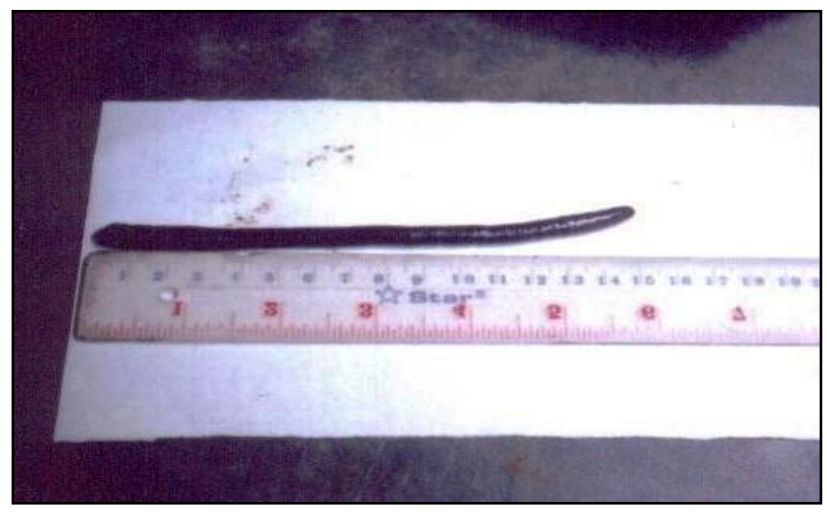

Gambar 4. Pheretima sp dewasa.

\section{Simpulan dan Saran}

\section{Simpulan}

Kelimpahan dan biomassa cacing tanah hanya terdapat pada musim penghujan. Pada musim tersebut cacing tanah hanya terdapat pada kedalaman 0-10 $\mathrm{cm}$. Kelimpahan cacing tanah tertinggi sampai terendah berturut-turut adalah pada tegakan mahoni (224.000 individu/ha), akasia (128.000 individu/ha), jati (96.000 individu/ha), lamtoro (64.000 individu/ha), gamal (64.000 individu/ha), dan eukaliptus (0 individu/ha). Biomassa cacing tanah berturutturut dari yang tertinggi sampai yang terendah yaitu pada tegakan mahoni $(105,6 \mathrm{~kg} / \mathrm{ha})$, gamal (54,4 kg/ha), akasia (19,2 kg/ha), jati (16 kg/ha), lamtoro $(6,4 \mathrm{~kg} / \mathrm{ha})$ dan eukaliptus $(0 \mathrm{~kg} / \mathrm{ha})$.
Kelimpahan cacing tanah dipengaruhi kadar lengas tanah. Biomassa cacing tanah dipengaruhi oleh $\mathrm{pH}$ dan berat volume tanah.

\section{Saran}

Perlu adanya penelitian lebih lanjut tentang faktor lingkungan tanah seperti kadar lengas tanah dan suhu tanah yang mampu membatasi aktivitas cacing tanah.

\section{Ucapan Terima Kasih}

Penulis mengucapkan terima kasih kepada Fakultas Biologi UGM, Pengelola Hutan Pendidikan Wanagama I dan Direktorat Jendral Pendidikan Tinggi atas bantuannya dalam pelaksanaan penelitian ini. 


\section{Daftar Pustaka}

Brady, N.C. 1985. The Nature and Properties of Soils. $9^{\text {th }}$ edition. Macmillan Publishing Company. New York, USA.

Brown, A.L. 1978. Ecology of Soil Organisms. Heinemann Educational Books. London.

Chuasavathi, T., Treloges, V. dan Ruaysoongnern, S. 2001. Earthworms Casts (Pheretema sp.) Nutrient Contents of Nampong Soil Series (Ustoxic Quartpsament) in Northeast Thailand. Pakistan J. of Biological Sciences, 4 (8): 973-976.

Hesse, P.R. 2002. A Textbook of Soil Chemical Analysis. Chemical Publishing Co., Inc., New York USA

Ma'shum, M.J.S. 2003. Biologi Tanah. Direkturat Jendral Pendidikan Tinggi Departemen Pendidikan Nasional. Jakarta.

Sabrina, D.T., Hanafi, M.M., Nor Azwady, A.A. dan Mahmud, T.M.M. 2009. Earthworm Population and Cast Properties in the Soils of Oil Palm Plantation. Malaysian J. of Soil Sci., 13: 29-42

Pritchett, W.L. 1979. Properties and Management of Forest Soils. John Wiley \& Sons, Inc. USA.

Smith, J., Anna, C. dan Paul. 2006. Baseline Biodiversity Surveys of The Soil Macrofauna of London's Green Spaces. Urban Ecosyst, 9: 337-349.

Suin, N.H. 1997. Ekologi Hewan Tanah. Bumi Aksara. Jakarta.

Supriyo, H. 2004. Perkembangan Fisik dan Vegetasi Wanagama I. Dari Bukit-bukit Gundul sampai ke Wanagama I. Penyunting: H. Soekiman Atmosoedrajo, R.I.S. Pramoedibyo dan Soebronto Ranoeprawiro. Yayasan Sarana Wana Jaya. Pp. 41-69.
Supriyo, H., Musyafa, Dewi, W. dan Agri, T.P. 2007a. The Abundance of Earthworms under Different Ages of Pine Stands (A case Study at Inceptisols, RPH Karanganyar, BKPH Sumberwringin, KPH Bondowoso, Jawa Timur). Proceedings of International Seminar Advances on Biological Sciences: Contribution Towards a Better Human Prosperity. Editors: A. P., Nugroho, B., Retnoaji, B. S., Daryono, K., dewi, Maryani, R., Susandarini, S. N., Marliana. Pp 160 - 162. Yogyakarta. Indonesia.

Supriyo, H., Musyafa, Dewi, W. dan Agri, T.P. 2007b. The Abundance of Earthworms under Several Tree Stands. Proceedings of Conferences on Natural Resources in the Tropics: Development and Commercialization of Tropical Natural Resources. Editors: I.B., Ipor, C.S., Tawan, P., Bulan, I., Jusoh, B.A., Fasihudin and Meekiong, K. Pp: 135-140. Sarawak. Malaysia.

Marhan, S. dan Stefan, S. 2005. Mixing of Different Mineral Soil Layers by Endogeic Earthworms Affects Carbon and Nitrogen Mineralization. Biol Fertil Soils, 42: 308-314.

Tian, G. 1992. Biological Effect on Plant Residues with Contrasting Chemical Composition on Plant and Soil under Humid Tropics. Ph.D. Thesis Wageningen Agricultural University, Netherland. 